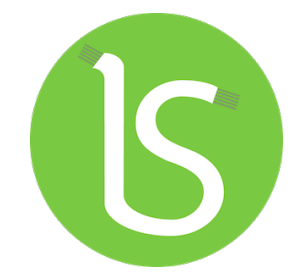

\title{
Transformar la enseñanza para una época de crisis
}

\author{
Griselda Hernández Méndeza \\ Edith Hernández Méndez
}

Resumen - La situación actual que vive el mundo en torno a la pandemia ocasionada por el COVID-19, fenómeno que trajo consigo muchas complicaciones, en especial en el campo escolar; puesto que intempestivamente la escuela cerró sus puertas y el profesorado apenas alcanzó a enlistar tareas como para quince días, sin imaginar que la cuarentena se prolongaría, a la fecha. La incertidumbre no se hizo esperar y los agentes educativos en todo el mundo, de inmediato, fomentaron el uso de innovadoras Tecnologías de la Información y la Comunicación (TIC) para solventar el problema. Las siguientes líneas constituyen nuestras reflexiones que, como profesoras, desarrollamos a partir de esta realidad. Sostenemos la tesis de que, más que concentrarse enfáticamente en el uso de las TIC como vías resolutivas al problema de educar a los estudiantes en esta época de crisis, se requieren otras concepciones y formas de enseñanza. No es que se descarten las TIC; al contrario, son indispensables, pero su uso será inútil si no se transforma la concepción de enseñanza. En ese sentido, el objetivo del artículo es propiciar la reflexión, especialmente de profesores y directivos, en torno a la necesidad de transformar paradigmas de enseñanza.

Palabras clave - Transformar la enseñanza, Complejidad, Perspectiva Crítica, Humanismo.

Abstract - The current situation that the whole world is living around the pandemic caused by COVID-19, a phenomenon that brought with it many complications, especially in the school field; since the school unexpectedly closed its doors and the teaching staff barely managed to list tasks for fifteen days, without imagining that the quarantine would last, to date. Uncertainties were immediate, and educational agents all over the world immediately encouraged the use of innovative Information and Communication Technologies (ICTs). The following lines constitute our reflections that, as teachers, we develop from living this reality closely. We support the thesis that, more than concentrating emphatically on the use of ICT as a way to solve the problem of educating students in this time of crisis, other conceptions and ways of teaching are required. It is not that ICTs are discarded, on the contrary, they are indispensable, but their use will be useless if the conception of teaching is not transformed. In this sense, the objective of the article is to encourage reflection, especially by teachers and managers, about the need to transform teaching paradigms.

Keywords - Transform Teaching, Complexity, Critical Perspective, Humanism.

\section{CÓMO CITAR}

HOW TO CITE:

Hernández Méndez, G., \&

Hernández Méndez, E. (2022).

Transformar la enseñanza para una época de crisis.

Interconectando Saberes, (13),

67-74.

https://doi.org/ 1 0.25009/is.v0il 3

.2693

Recibido: 2 de febrero de 2021 Aceptado: 22 de noviembre de 2021

Publicado: 31 de enero de 2022

${ }^{a}$ Universidad Veracruzana, México. E-mail: grihernandez@uv.mx

${ }^{\mathrm{b}}$ Universidad Autónoma de Quintana Roo, México. E-mail: edith@correo.uqroo.mx 


\section{INTRODUCCIÓN}

En pleno siglo $X X I$, la sociedad-mundo se ha quedado estupefacta ante un fenómeno de tal envergadura del que nadie tiene control, que amenaza la vida humana sin importar condición social, racial o credo; por supuesto nos referimos a la pandemia que presenciamos y que nos ha dejado anonadados, sobre todo al profesorado que, de repente, parecía paralizado para actuar.

¿Acaso no ya sabíamos por autores como Sacristán y Pérez Gómez (1998) que la práctica docente $y$, por ende, la enseñanza, es una realidad compleja que se define por su multidimensionalidad, simultaneidad, e impredictibilidad? ¿Por qué nos tomó de sorpresa ese suceso? Las respuestas son llanas porque, si bien todo docente sabe implícita o explícitamente que en el aula hay impredecibles y complicaciones, jamás nos imaginábamos algo como un virus contagioso de fácil propagación, que implicara encierro y distanciamiento social. Justo ese encierro y sus implicaciones nos condujeron a reflexionar en torno a las acciones que, como profesores, debimos y debemos tomar ante nuestra tarea de enseñar.

La transformación de la enseñanza ha sido preocupación de un vasto número de pedagogos desde hace siglos, y se ha centrado en el revocamiento de principios peculiares de la escuela tradicional, como el enciclopedismo, verbalismo exacerbado, autoritarismo, receptivismo, memorización excesiva, etcétera (Hernández, 20I I). Aun con tantas teorías y cursos de formación y actualización docente, persisten profesores que no pueden despojarse del todo de elementos del modelo de escuela tradicional o denominada vieja escuela, justamente porque fueron formados dentro de esa escuela y/o son herederos del paradigma racionalista cientificista, y además positivista, que inhibe ver aquello que se salga de esos esquemas.

El paradigma cientificista-positivista, observa a la ciencia como absoluta, dada, verdadera, certera, causalista; privilegia el método hipotéticodeductivo. Es reduccionista, determinista, atomístico (Malpica y Hernández, 2018).

Un paradigma es lo que posee en común una comunidad: mismas lecturas costumbres hábitos, acciones $y$, para el caso del profesorado, los mismos esquemas decimonónicos. Quizás ya quedó claro y superado el autoritarismo docente, esto es, abandonar el rol de autoritarios generales castigadores; sin embargo, hay cuestiones que aún perduran, como la sobre confianza que se tiene a lo que se enseña, al manejo de contenidos escolares como algo dado, fijo, incuestionable, inamovible. Esto conlleva a tener la necesidad de engancharse en la transmisión de conocimientos $y$, con ello, el verbalismo o exposición oral regresa a hacer su aparición escénica; ahora atrás de una pantalla digital.

¿Qué sucedió para el caso de la Universidad Veracruzana ahora que las clases presenciales eran imposibles y los profesores no estaban habilitados para usar las plataformas? La Universidad, de inmediato, formalizó manuales para usar la plataforma EMINUS y luego Zoom, entre otras, y aun así un número notable de profesores negados a la tecnología por muchas razones (principalmente por distancia generacional que complica el acceso y manejo de la tecnología, o por la obstinación de no querer implementarlas, o por dudas de su efectividad), continuaron enviando y recibiendo 
tareas sin retroalimentación. El exceso de tareas se hizo presente y las quejas de los alumnos también.

Para el caso de los otros niveles educativos, el problema fue mayor, pues en principio nadie pensó que se extendería el tiempo de la cuarentena y los profesores organizaron una serie de tareas para quince días aproximadamente. La incomunicación ha sido asunto de seria preocupación y más por los estudiantes y sus padres que no cuentan con medios tecnológicos. Hay que destacar la existencia de profesores realmente comprometidos, pero también aquellos que parecen no inmutarse.

Las tareas se vuelven asuntos prioritarios, así como las clases virtuales, $y$ aquellos profesores comprometidos invierten muchas horas preparando sus clases y revisando tareas. Por su parte, la institución, para validar que los maestros trabajan, les solicita reportes e informes. ¿Pero qué sucede en la realidad, sobre todo con los estudiantes? ¿Están aprendiendo, atendiendo? No podemos generalizar, pero sí centrarnos en la realidad: muchos estudiantes no están respondiendo como los profesores o la institución querría; se distraen, participan poco, se duermen en la clase virtual, tienen dificultades con los ejercicios o tareas, o se angustian con tanta tarea.

Aquellos profesores preocupados buscan en la pedagogía orientaciones prácticas, remitiéndose a la didáctica, pero en su sentido instrumental, pues buscan efugios pragmáticos, cuando aquí lo importante es el análisis real de lo que sucede. Es imprescindible el pensamiento crítico y complejo, e incluso la teoría humanista, para luego pensar en el cómo, pero antes vale preguntarse ¿para qué se enseña?

\section{¿QUÉ RECUPERAR DEL PENSAMIENTO COMPLEJO?}

Profesores y alumnos somos humanos que padecemos los efectos de la pandemia, el encierro, la incertidumbre, el desosiego, el temor a la inoculación; vulnerables todos de ser contagiados, de enfermar o morir. Motivar al estudiantado a que quiera aprender temas que para este momento no son útiles porque hay otras prioridades, resulta misión casi imposible.

Pero, veamos el todo y no solo la parte: no imputemos causas parciales y etiquetemos las actitudes de los alumnos como favorecedoras de la apatía o de la irresponsabilidad. Tampoco hagamos lo mismo con esos profesores que parecen desinteresados en su deber de enseñar.

Cuerpo docente y estudiantado son parte de un todo, de un sistema:

El enfoque de sistema, también denominado enfoque sistémico, significa que el modo de abordar los objetos y fenómenos no puede ser aislado, sino que tienen que verse como parte de un todo. No es la suma de elementos, sino un conjunto de elementos que se encuentran en interacción, de forma integral, que produce nuevas cualidades con características diferentes, cuyo resultado es superior al de los componentes que lo forman y provocan un salto de calidad. (Rosell y Más, 2003).

Las historias de vida, los habitus, la edad, personalidad, entre tantos elementos, inciden para actuar de determinada manera ante las situaciones y eso, precisamente, nos hace ser diferentes. Las condiciones de vida también son distintas, la salud, las interacciones, 
la estructura familiar, etcétera. A algunos alumnos les gusta la escuela y estudiar, y a otros, no, por ejemplo de acuerdo con Arnold y Osorio (1998):

En lo que a complejidad se refiere, nunca un sistema puede igualarse con el ambiente y seguir conservando su identidad como sistema. La única posibilidad de relación entre un sistema y su ambiente implica que el primero debe absorber selectivamente aspectos de éste. Sin embargo, esta estrategia tiene la desventaja de especializar la selectividad del sistema respecto a su ambiente, lo que disminuye su capacidad de reacción frente a los cambios externos. (p. 4).

Así, el comportamiento de un estudiante puede variar en relación con esa interacción con el ambiente. Un estudiante en su proceso de aprendizaje no responde sólo al docente como agente de interacción, sino a todo lo que significa como un sistema dinámico abierto, que se encamina a lo que Morín (2000) denomina principio hologramático. Un alumno es un/a muchacha (o), con o sin novia (o), hija(o) de familia, hermana(o), amiga(o), vecina(a), acomplejada(o), realizada(o), fortachóna( ) o enclenque, etc.; es un todo, no solo es alumno o alumna de una asignatura, en un horario particular; es un todo que muchas veces responde al narcisismo docentel, no por convicción, sino solo por aprobar, y eso parecen ignorar los profesores, sobre todo aquellos que se empeñan en

' El narcisismo responde a ese llamado, en búsqueda de querer convertirse en ese ideal, de reconocimiento, de amor, de volverse un Dios en el cosmos que representa el aula (Martínez Cuevas (2017) https://www.iztacala.unam.mx/errancia/vI5/PDFS_I/POLIETI CAS\%206\%20SOBRE\%20LA\%20CUESTION...\%20version\%20 papel.pdf exigir cantidad de tareas y sin sentido en este periodo de crisis.

A muchos profesores les cuesta aceptar que lo que enseñan no es tan importante, y menos en estos momentos, por eso los "memes"2 están expresando gran parte de la verdad; tanta tarea y sin significado propicia sentimientos aversivos en los estudiantes.

Por ese paradigma racionalista-cientificista, inherente en su formación, el profesor está convencido de que el estudiante debe aprender la cantidad de saberes "necesarios" para promover una materia o asignatura; saberes fijados en la mente que presupone como verdades absolutas, teorías e incluso leyes incuestionables. Lo que Morín (1999) cuestiona:

Es muy diciente el hecho de que la educación, que es la que tiende a comunicar los conocimientos, permanezca ciega ante lo que es el conocimiento humano, sus disposiciones, sus imperfecciones, sus dificultades, sus tendencias tanto al error como a la ilusión y no se preocupe en absoluto por hacer conocer lo que es conocer (p. I).

La verdad es una ilusión y al conocimiento solo se llega negando la posibilidad de su verdad. Se necesita despertar las incertidumbres de los alumnos, las dudas, la inquietud por construir saberes, consensuarlos, debatirlos, aniquilarlos. Por supuesto, dejar de ser protagonistas, pero eso le cuesta demasiado a un

${ }^{2}$ La palabra meme se utiliza en la cultura mexicana para referir a ideas, conductas o estilos que se extienden y generalizan culturalmente entre personas. La palabra fue utilizada por Richard Dawkingsen su libro El gen egoísta. Del griego "mimema" hace referencia a lo que es imitado, se generaliza y para el caso mexicano generalmente causa risa o burla. 
profesor, sea hombre o mujer y de diferente edad. Frente al pizarrón y delante de los estudiantes, se ha erigido como protagonista y ahora, tras una pantalla, quiere seguir siéndolo. Sin embargo, las condiciones son otras, tras su pantalla el profesorado está limitado, no logra mirarlos a todos y que ellos los miren a los ojos; es decir, no puede valerse de su kinésica o proxémica como elementos del lenguaje no verbal para apoyarse como lo hiciera en el aula. No puede ver qué hacen los alumnos que quitan su pantalla o cierran el audio. Hablar mucho en estas circunstancias es natural que provoque inevitable sueño en el alumnado (en los memes ellos denuncian esta realidad: se duermen).

Mucho hay que recuperar del pensamiento complejo, pero vamos a remitirnos a la teoría crítica.

\section{RESCATAR AL MENOS ALGUNOS PRINCIPIOS DE LA TEORÍA CRÍTICA}

En el contexto de la pandemia, pareciera que opera una psicología del miedo, que se esparce principalmente por los mensajes que transmiten los medios de comunicación, los cuales a veces desinforman $y$, lejos de provocar actitudes propositivas, generan ansiedad y temor. Distraer a los alumnos con las clases en línea o con tareas resulta positivo para evitar que salgan de casa y sean contagiados, --pues todo ser social requiere de la interrelación con los otros, y también funciona como un somnífero evasivo de la realidad, ya que es tan cruda que cuesta creer que sea cierto lo que acontece.

Al respecto ¿Qué rescatar de la teoría o pedagogía crítica? Por supuesto, la necesidad de volvernos críticos. Por principio, reconocer que los profesores somos reproductores de ideología hegemónica; como los demás, nos sometemos a las decisiones de gobiernos, de consorcios, de instituciones... con una docilidad sistémica (Bourdieu y Passeron, 1977; Foucault, 1984, entre tantos más pensadores críticos).

Seguimos orientando nuestras clases bajo la programación de contenidos, por cierto, impuesta exógenamente, que a fortiori queremos terminar, sin darnos cuenta de que los contenidos y los textos son parte de la cultura, son realidades $y$, por tanto, son pretextos para aprender la vida en la vida misma, que más vale poco bien aprendido que mucho por olvidar. El alumnado aprenderá si el contenido le significa algo, le encuentra sentido y aplicación, de lo contrario terminará por expelerlo, tal como Freinet (Hernández, 2009) refería como bulimia educativa.

Las tareas que se solicitan a los estudiantes requieren de un replanteamiento. Respondamos si de verdad con éstas demuestran aprender $\circ$ solo reproducen lo que los autores dicen, solo son "copia y pega" o peor aún, terminan con el dedo índice desgastado de tanto escribir para luego enviar la foto como muestra de "haber cumplido". ¿Estamos seguros de que con esos ejercicios matemáticos están listos para mostrar resolverlos con competencias y no solo porque mecanizan los pasos?

El pensamiento crítico obliga a hacer replanteamientos a nuestro actuar y buscar con reflexividad salidas creativas; no a creer que la didáctica resuelva mágicamente los problemas reales. Un ejemplo podría ser la modificación de contenidos (cantidad o temáticas vinculadas con el problema de la pandemia).

La didáctica, en su sentido instrumental, no ayuda, más sí genera dudas a los maestros. Necesitamos de una didáctica critica centrada en los problemas 
(como es el caso de la pandemia actual), en la vida y los acontecimientos; no en la linealidad de contenidos programáticos, porque insistimos, ¿a qué estudiante le resulta interesante el exceso de tareas y el cumplimiento de un programa lineal mientras enfrentan el encierro, el hastío de no ver a sus coetáneos, la necesidad de regresar a la normalidad, la ansiedad de tener de cerca contagiados o padres que pierden el trabajo, la angustia por no saber si mañana tendrán alimentos en su hogar, entre tantos problemas más?

\section{¿POR QUÉ LA TEORÍA HUMANISTA PARA ESTOS TIEMPOS DE CRISIS?}

Crisis expresa alteración en el desarrollo de un proceso, que puede ser de orden patológico, físico, psicológico, sociohistórico, político, espiritual...o todos estos al mismo tiempo.

Las crisis son los trances que nos permiten tomar conciencia de los sucesos y acciones, de que todas las cosas de este mundo material, alguna vez terminan. De acuerdo con Riveros (20l4), con las Guerras mundiales, se vivieron crisis y fue justo con estas que la teoría humanista se originó.

El mundo llegó a necesitar de una Psicología acorde a un desarrollo histórico que permitiera a la sociedad buscar y dar solución pacífica a los conflictos entre nacionales, que ya no podrían ser resueltos tecnológicamente. Era necesario descubrir una nueva forma de concebir esta ciencia cuyo paradigma imperante hasta 1945 no tenía mucho que ofrecer frente a los grandes problemas que el hombre tiene con el hombre, dicho en palabras de Martin Buber (1878-1965). Espiritualmente, Occidente toma conciencia de su incapacidad filosófica y psicológica para comprender la nueva dimensión de la guerra, la nueva interrogante de cómo resolver conflictos internacionales sin derramamiento de sangre. (p. 137).

Toda crisis daña a las personas de muchas maneras, tal es el caso de la situación que se vive ante la pandemia. El encierro, la paralización de actividades, de centros comerciales y recreativos, de la escuela y de tantos espacios más, genera crisis psicológica: algunos ya experimentan neurosis; otros, tristeza, preocupación, impotencia, nostalgia, soledad, insomnio...

Como toda crisis, esta también cesará, sin embargo, el desosiego y la desesperación se manifiestan: algunas personas atiestas de la cuarentena regresaron a sus habituales actividades exponiéndose y exponiendo a los otros. Quienes deciden resguardarse en casa también sufren el impacto del aislamiento, del tedio, la añoranza, entre tantos sentimientos más.

Estas emociones y sentimientos justifican la necesidad de la psicología humanista, que es considerada por varios psicólogos, sobre todo de corte neoconductista, como acientífica porque desde sus inicios se inspiró en disciplinas como el Arte universal, discurriendo con poetas y literatos sobre el fenómeno conocido como el drama humano, sin basamento científico. La psicología humanista se conforma por una constelación de destacados autores que tienen en común la búsqueda de conocimiento de lo propiamente humano, y provienen de diferentes disciplinas: filosofía, antropología, teología, las artes en sus muchas dimensiones, entre otras. 
Del profuso redimible de esta psicología se encuentran las actitudes de empatía y de noética; ahora sustentamos por qué. El profesorado necesita de actitudes de empatía que le conduzcan a mirar las cosas como las mira el otro y, si es posible, que las sienta como el otro. Solo así será consiente de que, ante una crisis que supone amenaza, lo que menos quiere el alumnado es aprender contenidos programáticos sin sentido. La empatía es la capacidad de comprender e inferir los sentimientos y emociones de los otros (Rogers, 1957).

La empatía también debería ser una actitud que tendríamos que desarrollar todos; por ejemplo, la sociedad juzga al profesorado por dedicarle poco tiempo a las clases virtuales que imparte, sin conocer a fondo lo que implica preparar y dar la clase detrás de una pantalla a alumno(a)s habituados generalmente a utilizar la tecnología, pero para propósitos de entretenimiento o diversión, muchas veces más que para lo académico.

Bajo estas consideraciones, esa actitud empática permitiría construir clases para cautivar emotivamente a los estudiantes dándole más peso a la emoción de aprender que a la asimilación de contenidos fijados por el programador educativo como importantes. Necesitamos de una mirada empática-holística para comprender a nuestros alumnos, quienes son más que mente y cuerpo, son espíritus y, desde allí podríamos repensar nuestras clases.

Vivimos ante una crisis que no podemos evadir y dar nuestras clases como si nada pasara. Nos toca desarrollar actitudes humanas, no solo aptitudes en TIC. Esta crisis nos cambiará, seremos otros o ya somos otros, esperemos que mejores humanos, mejores personas. Requerimos de una actitud noética que permita enfrentar esta crisis, sacándole el mejor partido, tal como lo hiciera Victor Frank en los campos de concentración. Allí donde el concepto de actitud de libertad y responsabilidad, así como el descubrimiento del humor fueron una alternativa al sufrimiento sin sentido (Frank, 1984). Los hombres sufren porque quieren, esto es, cada uno es responsable de lo que quiere sentir.

Así, más vale una actitud proactiva ante la crisis y aprovechar el tiempo que tenemos para vivir, convivir con los seres que más amamos, ejercitarnos, querernos, apapacharnos, leer, aprender por el deleite de aprender y no por imposición. De esto enganchémonos todos los profesores. La poesía, el arte, la literatura son elementos útiles para conectar nuestros contenidos y despertar el interés de los alumnos, que no está dormido, más bien no lo hemos sabido despertar.

\section{CONCLUSIONES}

Nuestro objetivo con este texto fue propiciar la reflexión, especialmente de profesores y directivos, en torno a la necesidad de transformar paradigmas de enseñanza. Para ello, partimos del presupuesto de transformar esquemas de enseñar, a partir de una concepción diferente de lo que implica enseñar y aprender ante una época de crisis, como es el caso de la crisis sanitaria COVID-I9.

Mientras observamos, por una parte, una preocupación de autoridades y profesorado centrada en el uso de las tecnologías para la impartición de clases, la distribución y calificación de tareas y/o actividades; por otra, poco se cuestiona la relevancia de las TIC en esta situación de aislamiento. En el ensayo, nos propusimos reflexionar un poco más allá de lo instrumental del uso de las herramientas de la información y la comunicación y sugerimos el cambio de paradigma de enseñar ahora 
ante la crisis a través de la recuperación de principios claves del pensamiento complejo, de la perspectiva pedagógica crítica y de la teoría humanista. Del primero, la noción de sistema, el holismo, lo hologramático y la negación de la verdad absoluta con la que se transmiten los contenidos escolares.

De la postura crítica, principios generadores de reflexión, de cuestionamiento ante la utilidad de los contenidos escolares y su sentido en el marco de la realidad y distintos contextos que enmarcan la vida de cada uno de los estudiantes. En esa línea, se retoma de la teoría humanista, las actitudes de empatía y la noética, justamente para buscar nuevas estrategias para hacer llegar a los alumnos no solamente saberes teóricos, sino también habilidades, y más aún actitudes para contrarrestar la situación que preocupa, que genera ansiedades, temores y una serie de sentimientos que no se pueden negar porque están en nuestras vidas y afectan a todos. Empero, no permitamos que nos afecte, en el sentido de la noética, puesto que somos responsables de lo que queremos sentir, más bien seamos proactivos con esa situación sacando el mejor provecho.

\section{REFERENCIAS}

Arnold, M. y Francisco, Osorio (1998). Introducción a los Conceptos Básicos de la Teoría General de Sistemas. Revista Electrónica de Epistemología de Ciencias Sociales Facultad de Ciencias Sociales Universidad de Chile.

Bourdieu. P. y J. Passeron (1977). La reproducción. Elementos para una teoría del sistema de enseñanza. Barcelona: Laia.

Frankl, V. (1984). La Idea Psicológica del Hombre. Madrid: Rialp.

Foucault, Michael (1984). Vigilar y castigar, México, Siglo XXI

Hernández, G. (2009). La complejidad en realidades diversas. México: IIESES.
Hernández, G. (20II). Transformar el subsuelo antes que la superficie. Narrativa de un aula. Revista Educación y Humanismo. (20). Simón Bolívar.

Malpica, S. y G. Hernández (2018) Desafíos para los docentes del siglo XXI. Transbordar nuevos paradigmas de enseñar. Revista Interconectando Saberes, (2).

Morin, E. (1988). El Método II. La vida de la vida. Madrid: Ediciones Cátedra

Morin, E. (1999). Los siete saberes necesarios para la educación del futuro. México: UNESCO.

Rogers K (1952). Client-centered psychotherapy, Scientific American, 187(5).

Rogers K (1957). The necessary and sufficient conditions of therapeutic personality change, Journal of Consulting Psyehoiogy, (2I).

Rosell, W, y Más, M. (2003). El enfoque sistémico en el contenido de la enseñanza. Revista Médica Superior, 17(2). La Habana.

Sacristán, G. y A. Pérez Gómez (1998). Comprender y transformar la enseñanza, España: Morata. 